\title{
Proinflammatory effects of the hemagglutinin protein of the avian influenza A (H7N9) virus and microRNA-mediated homeostasis response in THP-1 cells
}

\author{
SHAOBO ZHANG ${ }^{1,2^{*}}$, DAYONG GU ${ }^{3 *}$, XIAOXI OUYANG ${ }^{4}$ and WEIDONG XIE ${ }^{1}$ \\ ${ }^{1}$ Shenzhen Key Lab of Health Science and Technology, Division of Life Science \& Health, Graduate School at Shenzhen, \\ Tsinghua University, Shenzhen, Guangdong 518055; ${ }^{2}$ Center of Clinical Laboratory, Zhujiang Hospital, \\ Southern Medical University, Guangzhou, Guangdong 510282; ${ }^{3}$ Central Laboratory of Health Quarantine, \\ International Travel Health Care Center, Shenzhen Entry-exit Inspection and Quarantine Bureau, \\ Shenzhen, Guangdong 518033; ${ }^{4}$ Department of Health Inspection and Quarantine, School of Public Health, \\ Sun Yat-Sen University, Guangzhou, Guangdong 510080, P.R. China
}

Received October 17, 2014; Accepted July 10, 2015

DOI: $10.3892 / \mathrm{mmr} .2015 .4142$

\begin{abstract}
The pathology and immunological responses to hemagglutinin (HA) from H7N9 avian influenza viruses in humans remain unclear. The present study aimed to investigate the proinflammatory activity of the HA protein obtained from H7N9 viruses and the mechanisms underlying the homeostasis of microRNAs (miRNAs) in response to inflammatory stimuli. The expression of proinflammatory factors and miRNAs was assayed in the THP-1 cells using reverse transcription-quantitative polymerase chain reaction. Results showed that HA significantly increased the expression of interleukin (IL)-1 $\alpha$, IL- $1 \beta$ and IL- 6 in the THP-1 cells. Furthermore, HA and lipopolysaccharide exhibited synergic effects on the expression of IL- $1 \alpha$, IL-1 $\beta$ and IL-6 in the THP- 1 cells. Let-7e can target IL-6 and inhibit its expression. Notably, HA significantly increased let-7e expression in THP-1 cells and decreased the let-7e levels in the medium. However, the knockdown of toll-like receptor 4 (TLR4) significantly attenuated the effects of HA. These results indicate that the HA can induce inflammatory stress and may trigger an miRNA-mediated homeostasis response to
\end{abstract}

Correspondence to: Dr Weidong Xie, Shenzhen Key Lab of Health Science and Technology, Division of Life Science \& Health, Graduate School at Shenzhen, Tsinghua University, 2279 Lishui Road, Nanshan, Shenzhen, Guangdong 518055, P.R. China E-mail: xiewd@sz.tsinghua.edu.cn

Abbreviations: AIVs, avian influenza viruses; HA, hemagglutinin; IL-1 $\alpha$, interleukin $1 \alpha$; IL-1 $\beta$, interleukin $1 \beta$; IL-6, interleukin 6; TLRs, toll-like receptors; TNF- $\alpha$, tumor necrosis factor- $\alpha$

*Contributed equally

Key words: H7N9, hemagglutinin, microRNA, interleukin-6, toll-like receptor 4 , let-7e this stress. The effects of HA appeared to be mediated by the TLR4 pathway.

\section{Introduction}

Avian influenza viruses (AIVs), have repeatedly caused worldwide pandemics and are one of the leading infectious diseases with high rates of morbidity and mortality (1). AIV genomes consist of a single-stranded negative RNA with the following eight segments: Polymerase basic 2 (PB2), polymerase basic 1 (PB1), polymerase acid (PA), hemagglutinin (HA), nucleoprotein (NP), neuraminidase (NA), matrix (M) and non-structural polypeptides (NS). These eight segments encode 15 known proteins, including PA, PB2, PB1, HA, NP, NA, M1, M2, NS1 and NS2, as well as supplementary proteins (2). According to two viral membrane proteins, namely, HA and NA, AIVs can be divided into subtypes (H1-18 and N1-11, respectively) $(2,3)$.

HAs, which are a surface glycoprotein, are encoded by the fourth RNA segment. HAs facilitate the binding to and entrance of viruses into host cells via sialic acid (SAa) residues that are present on host cell surfaces (4). HAs appear to be predominantly involved in facilitating viral entry into the cell by specifically binding to the SAa surface receptor in host cells, and HA is likely able to alter surface antigenic properties by creating genetic mutations or reassortments (5). HAs are often used to design vaccines or major immunogenic components of influenza vaccines. HAs isolated from human strains specifically identify and bind SAa-2, 6, which is a receptor found on cells of the upper respiratory tract in humans. HAs also bind to SAa-2, 3, which is a receptor on lower respiratory tract cells in humans. The binding of HA and SAa is correlated with viral pneumonia. Moreover, mutations in HA are associated with epidemiology and clinical symptoms and outcomes $(6,7)$.

H7N9, which is a novel AIV subtype, is transmitted to humans and may be fatal by causing acute respiratory distress syndrome or severe pneumonia; however, the 
transmission mechanism of AIVs from person to person remain unclear $(8,9)$. More than 400 individuals were infected with H7N9 from March 2013 to April 2014, in China. Patients with H7N9 infections present with intense systemic inflammatory response syndrome that is concomitant with an anti-inflammatory response (10). HAs from the H7N9 virus cause pathological responses in hosts, and simultaneously hosts may resist or regulate this pathological damage by triggering protective homeostatic responses. However, the exact molecular mechanisms of the pathogenesis of H7N9 infection are not fully understood.

MicroRNAs (miRNAs), which are small non-coding RNAs, control the expression of several target mRNAs. miRNAs control the activity of $\sim 30 \%$ of all protein-coding genes in mammals (11). miRNAs also regulate immune and inflammatory responses $(12,13)$. In a previous study, miR-181a was involved in the homeostasis response to inflammatory stimulus (14). Patients infected with H7N9 showed increased expression of miR-20a, miR-106a, miR-17 and miR-376c, and decreased expression of let-7e in the blood (15). However, the functions of the miRNAs induced by H7N9 remain unclear. The present study aimed to assess the inflammatory response and self-regulatory mechanisms of the miRNAs, which are induced by HAs of H7N9 in THP-1 cells.

\section{Materials and methods}

Cell culture. THP-1, which is a human acute monocytic leukemia cell line, grows mainly in a suspended state. The THP-1 cell line was selected for the present study due to its shared characteristics with native monocyte-derived macrophage cells, as well as the fact that it is a well-developed cell model for inflammation research. The THP-1 cells were supplied by KeyGEN Biotech (Nanjing, China). The cells were cultured in Dulbecco's modified Eagle's medium (Invitrogen Life Technologies, Guangzhou, China) with $10 \%$ fetal bovine serum (Gibco, Life Technologies, Guangzhou, China) and incubated at $5 \% \mathrm{CO}_{2}$ at $37^{\circ} \mathrm{C}$. The cells were seeded in a 6 -well tissue plate at a density of $4.0 \times 10^{5}$ per well. An HA protein of the influenza virus (H7N9) A/Anhui/1/2013 (ACRO Biosystems, Beijing, China) was added to the incubated cells after the cells had been seeded for $12 \mathrm{~h}$. Cell samples were collected at $0,2,4,8,12$ and $24 \mathrm{~h}$ following treatment with $100 \mathrm{ng} / \mathrm{ml} \mathrm{HA}$ to analyze the proinflammatory factors and miRNAs. This procedure was performed to determine the optimal time of HA incubation, which would elicit the strongest effects on the cells. The THP- 1 cells were then treated with $\mathrm{HA}$ at $0,10,100$ and $200 \mathrm{ng} / \mathrm{ml}$ for $4 \mathrm{~h}$. Cell and medium samples, which were required for the assay of the proinflammatory factors and miRNAs, were collected. In another separate experiment, the THP-1 cells were incubated with $1 \mathrm{ng} / \mathrm{ml}$ lipopolysaccharide (LPS; Sigma-Aldrich, St. Louis, MO, USA) alone, $100 \mathrm{ng} / \mathrm{ml} \mathrm{HA}$ alone, and a combination of $1 \mathrm{ng} / \mathrm{ml} \mathrm{LPS}$ and $100 \mathrm{ng} / \mathrm{ml} \mathrm{HA}$ for $4 \mathrm{~h}$. The incubated THP-1 cells were used to investigate the synergic effect of HA and LPS on the expression of proinflammatory factors. This process was conducted as H7N9 virus infections are usually associated with bacterial infections.

Knockdown of TLR4. The small interfering (si)RNAs were transiently transfected into the cells at a density of
$4 \times 10^{5}$ cells/well and cultured in a 6 -well plate using a Lipofectamine 2000 reagent (Invitrogen Life Technologies). siTLR4 (GGAAUGAGCUAGUAAAGAA) was designed using siRNA Explorer software (developed by the group of Professor Yaou Zhang, Shenzhen Key Lab of Health Science and Technology, Division of Life Science and Health, Graduate School at Shenzhen, Tsinghua University, Shenzhen. China) and validated in preliminary trials. siRNA duplexes with random sequence were used as a negative control (UUGUACUACACAAAAGUACUG). These RNAs were purchased from Shanghai GenePharma Co., Ltd. (Shanghai, China). The medium was replaced with a fresh medium containing $100 \mathrm{ng} / \mathrm{ml} \mathrm{HA}$ after $12 \mathrm{~h}$ of transfection, and cell samples were collected for further biochemical assays (assaying levels of inflammatory factors and let-7e) $4 \mathrm{~h}$ after treatment with HA. All samples were immediately stored at $-80^{\circ} \mathrm{C}$ for future biochemical assays.

$m R N A$ reverse transcription-quantitative polymerase chain reaction $(R T-q P C R)$. The total RNA was extracted from the THP-1 cells using TRIzol ${ }^{\circledR}$ (Invitrogen Life Technologies) and from the cell medium using TRIzol LS Reagent (Invitrogen Life Technologies) according to the manufacturer's instructions. The RNA was reverse-transcribed to cDNA using a PrimeScript ${ }^{\mathrm{TM}}$ 1st Strand cDNA Synthesis kit (Takara Biotechnology (Dalian) Co., Ltd., Dalian, China) with an Alpha $^{\mathrm{TM}}$ Unit Block Assembly for DNA EngineH systems (Bio-Rad, Hercules, CA, USA). The RNA was then amplified using SYBR Green I dye (Takara Biotechnology (Dalian) Co., Ltd.) with an ABI PRISM 7300 Real time PCR system (Applied Biosystems, Foster, CA, USA) according to the manufacturer's instructions. In addition, the primers for the target genes were synthesized by Invitrogen Life Technologies, and actin was selected as an internal control for normalization (Table I). The fold change was calculated using the $2^{-\Delta \Delta \mathrm{Ct}}$ method of relative quantification.

miRNA RT-qPCR. The expression of hsa-let-7e was analyzed using an miRNA assay kit (Shanghai GenePharma Co., Ltd.) according to the manufacturer's instructions. miRNA RT-qPCR was performed using the same systems and machines as mRNA RT-qPCR. The hsa-let-7e was selected as let-7e can target interleukin (IL)-6 (http://www.targetscan. org/). A previous study demonstrated that let-7e decreased in the sera of patients with H7N9 (15). A U6 gene was used as the internal reference for normalization.

Statistical analysis. The data are expressed as the mean \pm standard deviation. Statistical significance of the data was evaluated by conducting a one-way analysis of variance using SPSS 13.0 (SPSS, Inc., Chicago, IL, USA). Newman-Keuls comparison was used to determine the source of significant difference where appropriate. $\mathrm{P}<0.05$ was considered to indicate a statistically significant difference.

\section{Results}

Incubation time with $H A$. After $4 \mathrm{~h}$ of incubation with HA, at a final concentration of $100 \mathrm{ng} / \mathrm{ml}$, a stable increase in the expression of IL-1 $\alpha$ and IL-6 (Fig. 1) was observed compared 
Table I. Primers for tested genes in THP-1 cells.

\begin{tabular}{|c|c|c|c|}
\hline Gene name & NCBI accession no. & Primers ( $5^{\prime}$ to $\left.3^{\prime}\right)$ & Size (bp) \\
\hline IL1A & NM_000575 & $\begin{array}{l}\text { Forward: ATCATGTAAGCTATGGCCCACT } \\
\text { Reverse: CTTCCCGTTGGTTGCTACTAC }\end{array}$ & 131 \\
\hline IL1B & NM_000576 & $\begin{array}{l}\text { Forward: CTCGCCAGTGAAATGATGGCT } \\
\text { Reverse: GTCGGAGATTCGTAGCTGGAT }\end{array}$ & 144 \\
\hline IL6 & NM_000600 & $\begin{array}{l}\text { Forward: ACTCACCTCTTCAGAACGAATTG } \\
\text { Reverse: CCATCTTTGGAAGGTTCAGGTTG }\end{array}$ & 149 \\
\hline TNFA & NM_000594 & $\begin{array}{l}\text { Forward: CСТСТСТСТАATCAGCССТСТG } \\
\text { Reverse: GAGGACCTGGGAGTAGATGAG }\end{array}$ & 220 \\
\hline GAPDH & NM_001256799 & $\begin{array}{l}\text { Forward: GGAGCGAGATCCCTCCAAAAT } \\
\text { Reverse: GGCTGTTGTCATACTTCTCATGG }\end{array}$ & 197 \\
\hline
\end{tabular}

IL, interleukin; TNF, tumor necrosis factor.

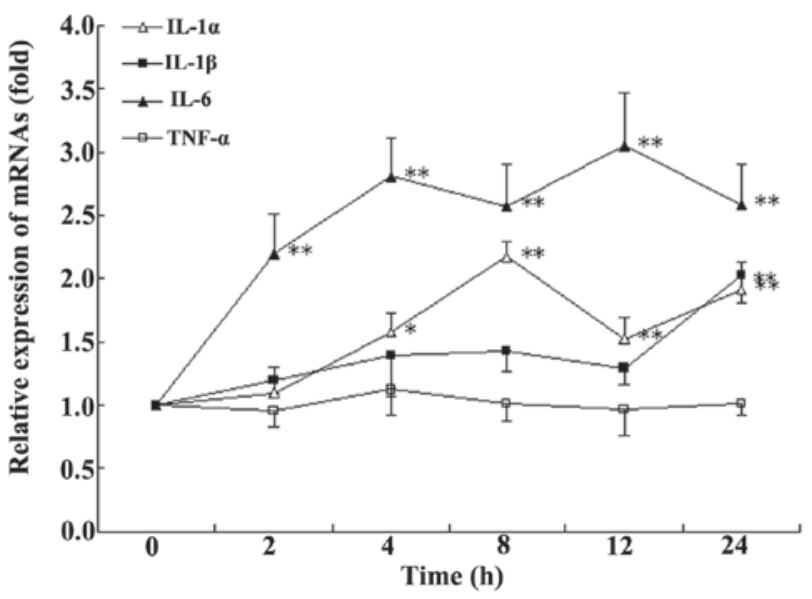

Figure 1. Changes in IL- $1 \alpha$, IL- $1 \beta$, IL- 6 and TNF- $\alpha$ in $100 \mathrm{ng} / \mathrm{ml}$ of HA-treated THP- 1 cells at different time points. ${ }^{*} \mathrm{P}<0.05$ and ${ }^{* *} \mathrm{P}<0.01 \mathrm{vs}$. $0 \mathrm{~h}$. The data are expressed as the mean \pm standard deviation $(\mathrm{n}=4)$. IL, interleukin; TNF, tumor necrosis factor.

with that at $0 \mathrm{~h}$. Therefore, $4 \mathrm{~h}$ incubation was selected for following experiments.

Effect of HA concentration on cytokine expression. HA at 10, 100 , and $200 \mathrm{ng} / \mathrm{ml}$ significantly promoted the IL-1 $\alpha$ and IL-6 expression in THP-1 cells (Fig. 2A). HA also showed a marked increase in the expression of IL-1 $\beta$; however, this was not identified to be significant. HA did not exhibit a significant effect on the expression of TNF- $\alpha$. In the following experiment, a concentration of $100 \mathrm{ng} / \mathrm{ml} \mathrm{HA}$ was selected for further investigation.

Effect of HA in combination with LPS on cytokine levels. The synergic effects of HA and LPS on the proinflammatory factors in THP-1 cells were also observed. Compared with the untreated control, treatment with $100 \mathrm{ng} / \mathrm{ml} \mathrm{HA}$ significantly increased the mRNA expression levels of IL-1 $\alpha$, IL-1 $\beta$ and IL-6, by 1.6, 2.0 and 4.2 fold, respectively. Treatment with LPS at $1 \mathrm{ng} / \mathrm{ml}$ significantly increased the mRNA expression
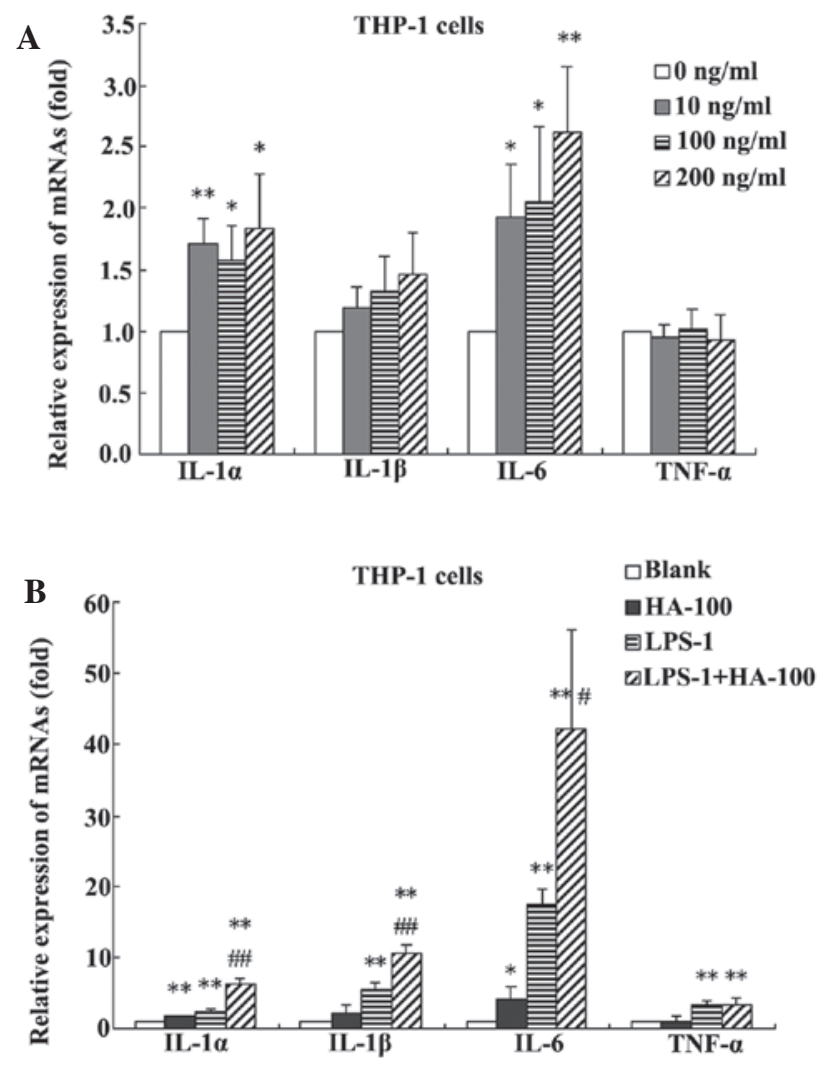

Figure 2. Changes in IL-1 $\alpha$, IL-1 $\beta$, IL-6 and TNF- $\alpha$ in (A) THP-1 cells treated with $\mathrm{HA}$ at different concentrations $(0,10,100$ and $200 \mathrm{ng} / \mathrm{ml})$. ${ }^{*} \mathrm{P}<0.05$ and ${ }^{* *} \mathrm{P}<0.01$, vs. the $0 \mathrm{ng} / \mathrm{ml}$-treated group. (B) THP-1 cells treated without HA (blank), with $100 \mathrm{ng} / \mathrm{ml}$ HA (HA-100), with $1 \mathrm{ng} / \mathrm{ml}$ LPS (LPS-1) or a combination of the two (HA-100+LPS-1). ${ }^{*} \mathrm{P}<0.05,{ }^{* *} \mathrm{P}<0.01$, vs. the blank group; ${ }^{\#} \mathrm{P}<0.05$, ${ }^{\#} \mathrm{P}<0.01$, vs. the LPS-1 group. Data are expressed as the mean \pm standard deviation $(n=4)$. IL, interleukin; TNF, tumor necrosis factor; HA, hemagglutinin; LPS, lipopolysaccharide.

levels of IL-1 $\alpha$, IL-1 $\beta$, IL-6 and TNF- $\alpha$ by $2.3,5.4,17.4$ and 3.2 fold, respectively. However, treatment with $\mathrm{HA}$ at $100 \mathrm{ng} / \mathrm{ml}$ in combination with LPS at $1 \mathrm{ng} / \mathrm{ml}$ significantly increased the mRNA expression levels of IIL- $1 \alpha$, IL-1 $\beta$, IL- 6 and TNF- $\alpha$, by $6.3,10.5,42.1$ and 3.4 fold, respectively. Furthermore, 


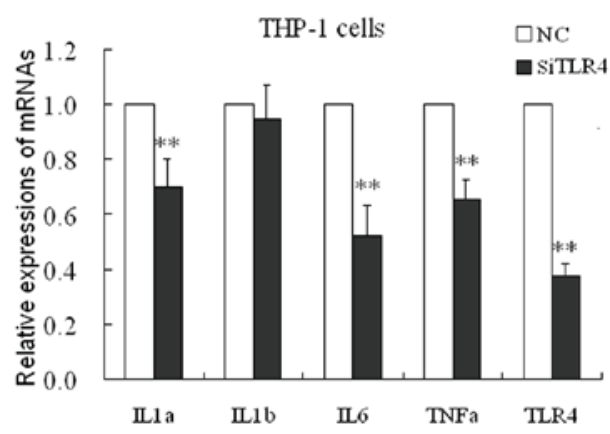

Figure 3. Changes in IL-1 $\alpha$, IL-1 $\beta$, IL-6, TNF- $\alpha$ and TLR4 in THP-1 cells treated with siTLR4. ${ }^{*} \mathrm{P}<0.05$ and ${ }^{* *} \mathrm{P}<0.01$ vs. NC. Data are expressed as the mean \pm standard deviation $(n=4)$. NC, HA-induced THP-1 cell treated with negative control; siTLR4, HA-induced THP-1 cell treated with siTLR4. IL, interleukin; TNF, tumor necrosis factor; TLR4, toll-like receptor 4; HA, hemagglutinin; si, small interfering.

A

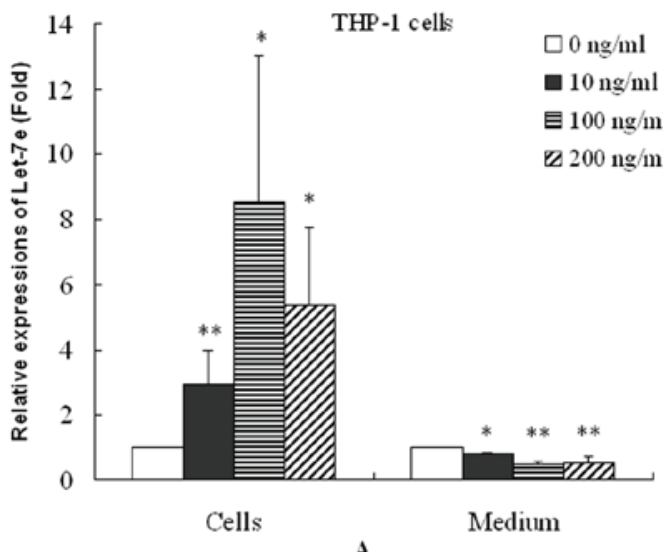

B

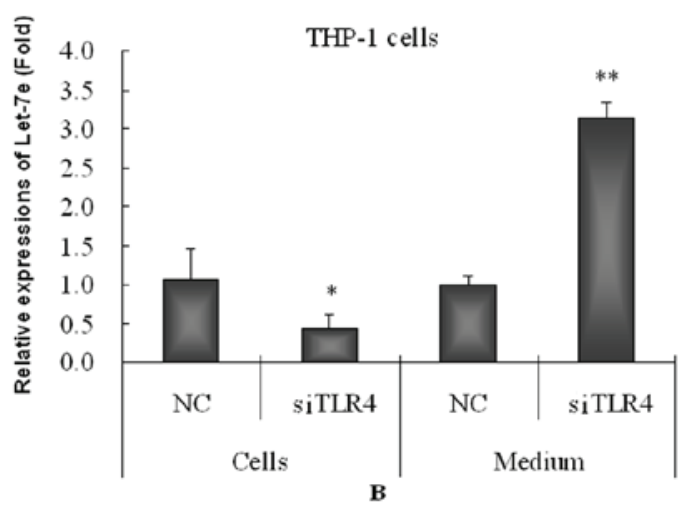

Figure 4. Changes of let-7e (A) in THP-1 cells and medium treated with HA at different concentrations $(0,10,100$ and $200 \mathrm{ng} / \mathrm{ml})$ and (B) in HA-induced THP-1 cells and medium following treatment with siTLR4. NC, HA-induced THP-1 cell treated with negative control; siTLR4, HA-induced THP-1 cel treated with siTLR4. ${ }^{*} \mathrm{P}<0.05$ and ${ }^{* *} \mathrm{P}<0.01$ vs. $0 \mathrm{ng} / \mathrm{ml}(\mathrm{A}) ;{ }^{*} \mathrm{P}<0.05,{ }^{* *} \mathrm{P}<0.01$ vs. NC (B). The data are expressed as the mean \pm standard deviation $(n=4)$. HA, hemagglutinin; TLR4, toll-like receptor 4; si, small interfering.

compared with HA alone, treatment with HA in combination with LPS significantly increased the mRNA expression levels of IL-1 $\alpha$, IL-1 $\beta$ and IL-6, by 4.0, 5.2 and 10.0 fold, respectively. Compared with LPS alone, treatment with HA in combination with LPS significantly increased the mRNA expression levels of IL- $1 \alpha$, IL-1 $\beta$ and IL- 6 by $2.8,2.0$ and 2.4 fold, respectively (Fig. 2B).
Effect of HA on TLR4. The mechanisms of upregulation of these proinflammatory factors by HA remain unclear. TLRs are important pattern recognition receptors that receptors mediate inflammatory stress. In the following experiment, it was determined whether HA resulted in inflammatory stress mediated by the toll-like receptor (TLR) pathway. siTLR4 was used, and the inhibition efficiency of the TLR4 mRNA expression was $\sim 37 \%$ (Fig. 3). Following transfection with siTLR4, levels of TLR4, IL-1 $\alpha$, IL-6, and TNF- $\alpha$ significantly decreased (Fig. 3) compared with the control.

Homeostatic response to inflammatory stress. Upregulation of proinflammatory factors usually activates the expression of anti-inflammatory factors and causes homeostasis responses to inflammatory stress. mRNAs also mediate the homeostasis response. Let-7 is a type of miRNA that binds to the 3'-untranslated region of IL-6 mRNA and inhibits IL-6 mRNA and protein expression. In this study, let-7e was significantly increased in the HA-induced THP-1 cells (Fig. 4A). However, HA significantly decreased the let-7e level in THP-1 cell culture medium and thus may inhibit the secretion of let-7e from the THP-1 cells enabling the maintenance of high intracellular let-7e levels.

Effect of TLR4 on let-7e. Furthermore, the knockdown of TLR 4 caused significant downregulation of let-7e in the THP-1 cells but increased the level of let-7e in the cell culture medium (Fig. 4B) compared with negative controls. These results suggested that knockdown of TLR4 reverses the effects of HA on let-7. It is likely that the increase in let-7e in the THP-1 cells and decrease in let-7e in cell culture medium by HA may be mediated by activating the TLR4 pathway.

\section{Discussion}

Molecular mechanisms of the pathogenesis of H7N9 infection remain unclear. By employing high throughput RNA-sequencing analysis of samples with and without H7N9 viral infection, Mei et al (16) found that differentially expressed genes are involved in several biological pathways associated with immunity and inflammation. In a study by $\mathrm{Wu}$ et al, the majority of H7N9-infected patients presented with systemic inflammatory response syndrome (10). The Th2-type inflammation in H7N9-infected patients with pre-existing chronic diseases likely contributes to the pathogenesis of H7N9 infection; this inflammation is correlated with poor clinical outcomes (17). In the LA-4 mouse lung cell line, CK1 (an $\mathrm{H} 7 \mathrm{~N} 9$ virus isolated from chickens) also induced high levels of IL-6 and cyclooxygenase- 2 mRNA (18). In the present study, it was demonstrated that HA from H7N9 can induce an inflammatory response in THP-1 cells; HA is likely an important pathological protein component of H7N9. In addition, HA and LPS exhibited a synergic effect on the promotion of expression of the inflammatory factors. The results suggested that combined H7N9 viral and bacterial infections may elicit enhanced inflammatory responses, compared with virus or bacterial infections alone.

Despite this, inflammatory stress can cause anti-inflammatory homeostasis response. Patients with avian H7N9 virus infection display intense systemic inflammatory 
response syndrome that is concomitant with an anti-inflammatory response (10). Anti-inflammatory mechanisms include increased anti-inflammatory factor (IL-4 and IL-10) levels (19). miRNAs also regulate inflammatory responses and mediate anti-inflammatory processes $(20,21)$; for example, Let- 7 can target IL-6 and inhibit IL-6 expression (22). In this study, the inflammatory response was associated with increased expression of let-7e. Increased let-7e may be associated with a homeostatic response to the inflammatory stimulus induced by HA since let-7e was predicted to target IL-6 and inhibit its production.

TLRs are important pathogen-recognition receptors in epithelial immune responses to microbial infection (23). TLRs are involved in the early innate viral inhibition of naturally occurring influenza (24). TLRs can activate inflammatory responses (25). Interaction of HA of the influenza A viruses (IAV) with the cell surface is a key factor for virus entry and productive infection of the cell (26). HA proteins from H5N1 and $2009 \mathrm{H} 1 \mathrm{~N} 1$ viruses were able to induce dendritic cell (DC) activation of murine DCs in a MyD88/TLR4 dependent manner (27). Nucleic acid-recognizing receptors (mainly RIG-I and TLRs) are the most extensively investigated pattern recognition receptors for IAVs (28). In this study, HA proteins from H7N9 appeared to not only activate inflammatory responses but also cause miRNA homeostasis to this inflammatory stress, dependent on the TLR4 pathway.

In addition, miRNAs can be transported from donor cells to recipient cells; these RNAs (i.e., let-7b) function in a novel manner as ligands of TLRs (29). The structure of let-7e is similar to let-7b. In this study, the HA of H7N9 inhibited the secretion of let-7e. This effect may be useful in preventing an excessive inflammatory response. Zhu et al demonstrated that patients infected with H7N9 showed decreased let-7e in the sera (15), indicating that cells of these patients attempted to trigger a protective response to avoid severe inflammatory damage in specific organs or tissues. A number of the H7N9-infected patients did not exhibit obvious systemic inflammation compared with the healthy controls (17), although the majority of the H7N9-infected patients $(\sim 74 \%)$ presented with systemic inflammatory response syndrome (10). However, the mechanisms that mediated the inhibitory effect on let-7 secretion by HA remain unclear although its secretion was also dependedent on the TLR4 pathway.

In conclusion, this study showed that HA significantly promoted the expression of proinflammatory factors, such as IL-1 $\alpha$ and IL-6. HA also produced a homeostatic response to inflammatory stress by regulating let-7e production and secretion. The inflammatory stress and miRNA homeostatic responses were mediated by TLR 4 mechanisms. The present study provided evidence that HA, one of the most important proteins of the H7N9 virus, directly causes the inflammatory response of immune cells in humans, but simultaneously triggers compensatory protective responses via miRNA mechanisms. Furthermore, the present study also demonstrated that the interaction between miRNAs and mRNAs may be regulated by immune cell signaling pathways. Therefore, host cells have a delicate biological network associating miRNAs and mRNAs, which protects against the invasion of H7N9 viruses. The results of the present study may prove useful in understanding the potential pathological mechanisms underlying
H7N9 infection, or to identify novel biomarkers for H7N9 virus infection. To further elucidate the interaction between miRNAs and mRNAs against the invasion of H7N9 viruses, future studies are required to identify more functional proteins of the H7N9 virus, or miRNAs in host cells.

\section{Acknowledgements}

The present study was supported by grants from the National Natural Science Foundation of China (grant nos. 81373460 and 81072680), the Shenzhen Science and Technology R\&D Foundation (grant nos. SGLH20121008144756945 and ZYC201105170341A), the Natural Science Foundation of Guangdong Province (grant no. 2014A030313744), the China Scholarship Council (grant no. 201308440130), the ITF Grant (grant no. GHX/002/12SZ) and the Key Lab Promotion Grant of Shenzhen (grant no. ZDSY20120619141025668).

\section{References}

1. Hayward AC, Fragaszy EB, Bermingham A, Wang L, Copas A, Edmunds WJ, Ferguson N, Goonetilleke N, Harvey G, Kovar J, et al: Comparative community burden and severity of seasonal and pandemic influenza: Results of the Flu watch cohort study. Lancet Respir Med 2: 445-454, 2014.

2. Le TH and Nguyen NT: Evolutionary dynamics of highly pathogenic avian influenza A/H5N1 HA clades and vaccine implementation in Vietnam. Clin Exp Vaccine Res 3: 117-127, 2014.

3. Alamares-Sapuay JG, Martinez-Gil L, Stertz S, Miller MS, Shaw ML and Palese P: Serum- and glucocorticoid-regulated kinase 1 is required for nuclear export of the ribonucleoprotein of influenza A virus. J Virol 87: 6020-6026, 2013.

4. Casalegno JS, Ferraris O, Escuret V, Bouscambert M, Bergeron C, Linès L, Excoffier T, Valette M, Frobert E, Pillet S, et al: Functional balance between the hemagglutinin and neuraminidase of influenza a (H1N1) pdm09 HA D222 variants. PLoS One 9: e104009, 2014.

5. Miotto O, Heiny AT, Albrecht R, García-Sastre A, Tan TW, August JT and Brusic V: Complete-proteome mapping of human influenza a adaptive mutations: Implications for human transmissibility of zoonotic strains. PLoS One 5: e9025, 2010.

6. Houng HS, Garner J, Zhou Y, Lyons A, Kuschner R, Deye G, St Clair K, Douce RW, Chicaiza W, Blair PJ, et al: Emergent 2009 influenza A (H1N1) viruses containing HA D222N mutation associated with severe clinical outcomes in the Americas. J Clin Virol 53: 12-15, 2012.

7. Wang B, Dwyer DE, Soedjono M, Shi H, Matlho K, Ratnamohan M, Blyth C, McPhie K, Cunningham AL and Saksena NK: Evidence of the circulation of pandemic influenza (H1N1) 2009 with D222D/G/N/S hemagglutinin polymorphisms during the first wave of the 2009 influenza pandemic. J Clin Virol 52: 304-306, 2011.

8. Dai J, Zhou X, Dong D, Liu Y, Gu Q, Zhu B, Wu C and Cai H: Human infection with a novel avian-origin influenza A (H7N9) virus: Serial chest radiographic and CT findings. Chin Med J (Engl) 127: 2206-2211,2014.

9. Ren L, Yu X, Zhao B, Wu F, Jin Q, Zhang X and Wang J: Infection with possible precursor of avian influenza A (H7N9) virus in a child, China, 2013. Emerg Infect Dis 20: 1362-1365, 2014.

10. Wu W, Shi Y, Gao H, Liang W, Sheng J and Li L: Immune derangement occurs in patients with $\mathrm{H} 7 \mathrm{~N} 9$ avian influenza. Crit Care 18: R43, 2014.

11. Li M, Marin-Muller C, Bharadwaj U, Chow KH, Yao Q and Chen C: MicroRNAs: Control and loss of control in human physiology and disease. World J Surg 33: 667-684, 2009.

12. Zhu S, Pan W and Qian Y: MicroRNA in immunity and autoimmunity. J Mol Med (Berl) 91: 1039-1050, 2013.

13. Rebane A and Akdis CA: MicroRNAs: Essential players in the regulation of inflammation. J Allergy Clin Immunol 132: 15-26, 2013.

14. Xie W, Li Z, Li M, Xu N and Zhang Y: miR-181a and inflammation: miRNA homeostasis response to inflammatory stimuli in vivo. Biochem Biophys Res Commun 430: 647-652, 2013. 
15. Zhu Z, Qi Y, Ge A, Zhu Y, Xu K, Ji H, Shi Z, Cui L and Zhou M: Comprehensive characterization of serum microRNA profile in response to the emerging avian influenza A (H7N9) virus infection in humans. Viruses 6: 1525-1539, 2014.

16. Mei B, Ding X, Xu HZ and Wang MT: Global gene expression changes in human peripheral blood after H7N9 infection. Gene 551: 255-260, 2014.

17. Han J, Zhang N, Zhang P, Yang C, Jin M, Yang J, Wu X, Liu G, Ji L, Zhang C, et al: Th2-type inflammation under conditions of pre-existing chronic disease is associated with liver damage in patients with avian influenza H7N9 virus. Microbes Infect 16: 672-677, 2014.

18. Li C, Li C, Zhang AJ, To KK, Lee AC, Zhu H, Wu HW, Chan JF, Chen H, Hung IF, et al: Avian influenza a H7N9 virus induces severe pneumonia in mice without prior adaptation and responds to a combination of zanamivir and COX-2 inhibitor. PLoS One 9: e107966, 2014.

19. Asseman $\mathrm{C}$ and von Herrath $\mathrm{M}$ : Regulation of viral and autoimmune responses. Novartis Found Symp 252: 239-253, discussion 253-267, 2003.

20. Xie W, Li M, Xu N, Lv Q, Huang N, He J and Zhang Y: MiR-181a regulates inflammation responses in monocytes and macrophages. PLoS One 8: e58639, 2013.

21. Singh RP, Massachi I, Manickavel S, Singh S, Rao NP, Hasan S, Mc Curdy DK, Sharma S, Wong D, Hahn BH and Rehimi H: The role of miRNA in inflammation and autoimmunity. Autoimmun Rev 12: 1160-1165, 2013.
22. Iliopoulos D, Hirsch HA and Struhl K: An epigenetic switch involving NF-kappaB, Lin28, Let-7 MicroRNA and IL6 links inflammation to cell transformation. Cell 139: 693-706, 2009.

23. Chen XM, Splinter PL, O'Hara SP and LaRusso NF: A cellular micro-RNA, let-7i, regulates toll-like receptor 4 expression and contributes to cholangiocyte immune responses against Cryptosporidium parvum infection. J Biol Chem 282: 28929-28938, 2007.

24. Lee N, Wong CK, Hui DS, Lee SK, Wong RY, Ngai KL, Chan MC, Chu YJ, Ho AW and Lui GC: Role of human Toll-like receptors in naturally occurring influenza A infections. Influenza Other Respir Viruses 7: 666-675, 2013.

25. Gribar SC, Anand RJ, Sodhi CP and Hackam DJ: The role of epithelial toll-like receptor signaling in the pathogenesis of intestinal inflammation. J Leukoc Biol 83: 493-498, 2008.

26. Ramos I and Fernandez-Sesma A: Cell receptors for influenza a viruses and the innate immune response. Front Microbiol 3: $117,2012$.

27. Liu WC, Lin SC, Yu YL, Chu CL and Wu SC: Dendritic cell activation by recombinant hemagglutinin proteins of H1N1 and H5N1 influenza A viruses. J Virol 84: 12011-12017, 2010.

28. García-Sastre A: Induction and evasion of type I interferon responses by influenza viruses. Virus Res 162: 12-18, 2011.

29. Chen X, Liang H, Zhang J, Zen K and Zhang CY: microRNAs are ligands of Toll-like receptors. RNA 19: 737-739, 2013 